\title{
【 LETTERS TO THE EDITOR 】
}

\section{A Case Series of Acute Kidney Injury during Anti-tuberculosis Treatment}

Key words: acute kidney injury, Rifampicin, desensitization

\section{(Intern Med 58: 3495, 2019)}

(DOI: 10.2169/internalmedicine.3448-19)

The Author Replies We appreciate Dr. Fukuchi and colleagues for their prompt comment on our article. We describe the details of the two patients who died. One patient was referred to our hospital because his acute kidney injury (AKI) relapsed after Rifampicin (RIF) desensitization in a previous hospital. His renal function did not improve despite stopping all anti-tuberculosis (TB) drugs and administering steroids. When the patient was transferred to our hospital, his blood pressure was $<80 \mathrm{mmHg}$, and he had severe delirium. We sedated him and started continuous renal replacement therapy (CRRT). However, the patient could not tolerate CRRT due to his unstable vital signs and continuing delirium. In addition, he developed massive pleural effusion and generalized edema. The patient finally developed severe bacterial pneumonia and died of respiratory failure three days after his referral to our hospital. Therefore, we were unable to restart the anti-TB drugs. The other patient was over 80 years old and developed AKI after Isoniazid, RIF and Ethambutol administration. The patient had severe malnutrition when diagnosed with active pulmonary TB. We stopped all anti-TB drugs and administered steroids. After his renal function improved, we started RIF desensitization. However, his AKI relapsed only a short while later. The patient's general condition did not recover, and he became continuously bedridden. He finally developed aspiration pneumonia and acute respiratory distress syndrome. His ultimate cause of death was respiratory failure.

The author states that he has no Conflict of Interest (COI).

\section{Kentaro Sakashita}

The Internal Medicine is an Open Access journal distributed under the Creative Commons Attribution-NonCommercial-NoDerivatives 4.0 International License. To view the details of this license, please visit (https://creativecommons.org/licenses/ by-nc-nd/4.0/). 